\title{
Role of Efficient Neurotransmitter Release in Barrel Map Development
}

\author{
Hui-Chen Lu, ${ }^{1}$ Daniel A. Butts, ${ }^{2}$ Pascal S. Kaeser, ${ }^{3}$ Wei-Chi She, ${ }^{1}$ Roger Janz, ${ }^{4}$ and Michael C. Crair ${ }^{1}$ \\ ${ }^{1}$ Department of Neuroscience, Program in Developmental Biology, Baylor College of Medicine, Houston, Texas 77030, ${ }^{2}$ Department of Neurobiology, \\ Harvard Medical School, Boston, Massachusetts 02115, ${ }^{3}$ Howard Hughes Medical Institute, Center for Basic Neuroscience, UT Southwestern Medical \\ Center, Dallas, Texas 75390, and ${ }^{4}$ Department of Neurobiology and Anatomy, W. M. Keck Center for the Neurobiology of Learning and Memory, University \\ of Texas-Houston Medical School, Houston, Texas 77030
}

Cortical maps are remarkably precise, with organized arrays of thalamocortical afferents (TCAs) that project into distinct neuronal modules. Here, we present evidence for the involvement of efficient neurotransmitter release in mouse cortical barrel map development using barrelless mice, a loss-of-function mutant of calcium/calmodulin-activated adenylyl cyclase I (AC1), and mice with a mutation in Rab3-interacting molecule $1 \alpha(\operatorname{RIM} 1 \alpha)$, an active zone protein that regulates neurotransmitter release. We demonstrate that release efficacy is substantially decreased in barrelless TCAs. We identify RIMs as important phosphorylation targets for AC1 in the presynaptic terminal. We further show that RIM1 $\alpha$ mutant mice have reduced TCA neurotransmitter release efficacy and barrel map deficits, although not as severe as those found in barrelless mice. This supports the role of RIM proteins in mediating, in part, $\mathrm{AC} 1$ signaling in barrel map development. Finally, we present a model to show how inadequacies in presynaptic function can interfere with activitydependent processes in neuronal circuit formation. These results demonstrate how efficient synaptic transmission mediated by AC1 function contributes to the development of cortical barrel maps.

Key words: cAMP; PKA; neurotransmitter release; cortical map; somatosensory; short-term plasticity; barrels

\section{Introduction}

The mouse primary somatosensory cortex is characterized by a row-and-arc pattern of "barrels" in cortical layer IV, replicating the arrangement of whiskers on the snout (Woolsey and Van der Loos, 1970; Killackey and Leshin, 1975). Each cylindrical barrel is composed of two parts: a presynaptic component with aggregates of thalamocortical afferents (TCAs) that relay sensory information from a single whisker; and a postsynaptic component with discrete rings of layer IV neurons that project their dendrites inward to synapse on one cluster of TCAs.

The precise mapping of facial whiskers to cortical barrels requires the coordinated development of TCAs and the dendrites of postsynaptic cortical neurons. Several lines of evidence suggest that input from the sensory periphery is instructive in this process. First, in

\footnotetext{
Received Sept. 19, 2005; revised Jan. 16, 2006; accepted Jan. 21, 2006.

H.-C.L. was supported by National Institute of Neurological Disorders Grant NS48884, American Heart Association Grant 0465158 Y, and the Gordon and Mary Cain Foundation. D.A.B. was supported by a Charles A. King Trust postdoctoral fellowship (Bank of America CoTrustee, Boston, MA). R.J. was supported by the W. M. Keck Foundation. M.C.C. was supported by National Institute of Mental Health Grant MH62639, the Merck and Klingenstein Foundations, and Mental Retardation Research Center at Baylor College of Medicine Grant HD24064. We thank Drs. R. Heidelberger, C. Rosenmund, and T. C. Südhof and members of the Crair laboratory for comments and discussion on this manuscript. Anti-phosphorylated RIMs and synapsin antibodies were generous gifts provided by Drs. G. Lonart and P. Greengaurd. The Developmental Studies Hybridoma Bank (University of lowa) provided the anti-SV2 antibody.

Correspondence should be addressed to either of the following: Hui-Chen Lu, The Cain Foundation Laboratories, Department of Pediatrics, Division of Neurology/Developmental Neuroscience, Baylor College of Medicine, 6621 Fannin Street, MC3-6365, Houston, TX 77030, E-mail: hclu@bcm.tmc.edu; or Michael C. Crair, Department of Neuroscience, Baylor College of Medicine, One Baylor Plaza, S-603, Houston, TX 77030, E-mail: mcrair@bcm.tmc.edu. DOI:10.1523/JNEUROSCI.3956-05.2006
}

Copyright $\odot 2006$ Society for Neuroscience $\quad$ 0270-6474/06/262692-12\$15.00/0 mutant mice with an atypical number of whiskers, there is close correspondence between the barrel pattern in the cortex and the pattern of whiskers on the snout (Van der Loos and Dorfl, 1978; Van der Loos et al., 1984). Second, embryonic visual cortex transplanted to a location corresponding to the primary somatosensory cortex forms barrels (Schlaggar and O'Leary, 1991). Third, knocking out the serotonin transporter, which is expressed in TCAs but not in cortical neurons, leads to a disruption of the barrel map (Persico et al., 2001). Finally, presynaptic $5-\mathrm{HT}_{1 \mathrm{~B}}$ receptors on TCAs play an essential role in the barrel phenotype of monoamine oxidase A mutants (Salichon et al., 2001; Rebsam et al., 2002). Despite the evidence for an instructive role of the sensory periphery in barrel map development, an integral role for the cortex in this process has also been well documented. For example, introducing an ectopic source of the morphogen fibroblast growth factor 8 (FGF8) into posterior cortex produces a duplicate barrel map (Fukuchi-Shimogori and Grove, 2001), and the cortex-specific deletion of the NMDA receptor subunit NR1 severely disrupts barrel map development (Iwasato et al., 2000; Datwani et al., 2002; Lee et al., 2005). Thus, it is likely that interplay between cortical neurons and TCAs regulates the emergence of a barrel pattern.

Barrelless $(b r l)\left(A d c y 1^{b r l}\right)$ mice have a loss-of-function mutation in the adenylyl cyclase I (AC1) gene (Abdel-Majid et al., 1998). In barrelless, TCAs reach their cortical target but do not cluster into barrels (Van der Loos et al., 1986; Welker et al., 1996), despite normal subcortical barrel structures in the somatosensory thalamus and brainstem. In vivo single-cell recordings from the presumptive barrel field of barrelless mice show that layer IV 
neurons have somatotopically appropriate receptive fields but respond inappropriately to stimulation of more than one facial whisker. We described previously how deficiencies in postsynaptic AMPA receptor (AMPAR) trafficking and long-term synaptic plasticity at thalamocortical (TC) synapses in barrelless mice likely contribute to their phenotype (Lu et al., 2003). However, barrel defects in barrelless mice are quite severe, with no evidence of a barrel pattern in TCAs or cortical layer IV neurons. This is unexpected if the locus of the deficit is purely postsynaptic, as other barrel mutant mice with presumed postsynaptic deficits, such as cortex-specific NMDA receptor subunit 1 (Cx-NR1) mutant mice (Iwasato et al., 2000) and phospholipase C- $\beta 1$ (PLC$\beta 1$ ) mutant mice (Erzurumlu and Kind, 2001; Hannan et al., 2001), show much more severe abnormalities in cortical layer IV neuron barrel patterning than in TCA clustering. The complete absence of a barrel pattern in barrelless mice suggests functional deficits may also exist in the presynaptic compartment of TC synapses in barrelless mice.

We present electrophysiological evidence for neurotransmitter release defects in barrelless mutant mice. We then use biochemical techniques to demonstrate that reduced AC1dependent phosphorylation of Rab3-interacting molecules (RIMs), active zone proteins critical in regulating neurotransmitter release, contributes to these deficits in barrelless mice. We further show that RIM1 $\alpha$ mutant mice have TCA neurotransmitter release defects and impaired barrel maps, confirming that the efficient release of neurotransmitter contributes to barrel map development. Finally, we present a computational model that demonstrates how inadequacies in presynaptic function can disrupt activity-dependent segregation of sensory afferents into an organized topographic map.

\section{Materials and Methods}

Electrophysiology. Acute thalamocortical brain slices, standard artificial CSF (ACSF), and whole-cell "internal" solutions were prepared as described previously (Lu et al., 2001). The ACSF was saturated with $95 \% \mathrm{O}_{2}$ and $5 \% \mathrm{CO}_{2}$ and consists of the following (in mM): $124 \mathrm{NaCl}, 5 \mathrm{KCl}, 1.25 \mathrm{NaH}_{2} \mathrm{PO}_{4}, 1.3$ $\mathrm{MgSO}_{4}, 2 \mathrm{CaCl}_{2}, 26 \mathrm{NaHCO}_{3}$, and 11 glucose, $\mathrm{pH} 7.2,300-310$ mOsm. Experiments were performed at room temperature $\left(\sim 26^{\circ} \mathrm{C}\right)$. The whole-cell recording solution contained the following (in $\mathrm{mm}$ ): 99 cesium gluconate, $17.5 \mathrm{CsCl}, 8 \mathrm{NaCl}$, 10 HEPES, 0.2 EGTA, $4 \mathrm{Mg}$-ATP, $0.3 \mathrm{GTP}, 7$ phosphocreatine, and 10 BAPTA, pH 7.2, 290-300 mOsm. BAPTA was included to prevent inadvertent potentiation in the postsynaptic compartment. Wholecell voltage-clamp recordings were used to record from layer IV neurons in somatosensory cortex using a MultiClamp 700A (Molecular Devices, Union City, CA). Stimuli (30-300 $\mu$ A; $0.1 \mathrm{~ms}$ ) were applied through bipolar sharpened and insulated stainless steel microelectrodes (FHC, Bowdoinham, ME) placed into the ventrobasal thalamus. Data were collected with $10 \mathrm{kHz}$ sampling with $5 \mathrm{kHz}$ filter and analyzed on-line using a computer-driven acquisition system (PCS with National Instrument AD boards; National Instruments, Austin, TX) and software that was written within the Igor programming environment. Input and series resistances were measured continuously to evaluate and monitor the health of the cell. Responses were considered to be monosynaptic only if they exhibited short and constant latencies that did not change with increasing stimulus intensity. To eliminate inhibitory currents, $100 \mu \mathrm{m}$ picrotoxin or $10 \mu \mathrm{M}$ GABAzin (Tocris Cookson, Ellisville, MO) was included in the ACSF. To measure NMDA currents, the cell was held at $+40 \mathrm{mV}$ and $10 \mu \mathrm{M}$ 2,3-dihydro-6-nitro-7-sulfamoylbenzo $(f)$ quinoxaline (NBQX; Tocris Cookson) was used to block AMPARs. For (+)-5-methyl-10,11-dihydro-5 $H$-dibenzo [a,d] cyclohepten5,10-imine maleate (MK801) experiments, NMDA current was isolated and only cells responding with a significant amount of NMDA current $(>15 \mathrm{pA})$ were used. After acquiring a stable baseline response (15-20 min), the stimulation was stopped and ACSF containing (+)-MK801 (40 $\mu \mathrm{M}$; Tocris Cookson) was perfused onto the slice ( $1 \mathrm{ml} / \mathrm{min}$ flow rate). After $10 \mathrm{~min}$ (to allow enough time for MK801 to equilibrate in the recording chamber), we resumed stimulation and recorded until no NMDA current could be detected for $>5 \mathrm{~min}$. The time course of MK801-dependent blockade was analyzed by normalizing all of the responses to the amplitude of the first NMDA response after MK801 was applied, and the blockade rates were estimated by fitting an exponential function to the decay.

For calcium-dependence experiments, NMDA-EPSCs were isolated and evoked at $0.2-0.33 \mathrm{~Hz}$ for a period of $15-20 \mathrm{~min}$ at $2 \mathrm{~mm}\left[\mathrm{Ca}^{2+}\right]$ at first to achieve a stable baseline for NMDA-EPSCs, and then the external $\left[\mathrm{Ca}^{2+}\right]$ was sequentially decreased to $1.75-0.5 \mathrm{~mm}\left[\mathrm{Ca}^{2+}\right]$ while the $\left[\mathrm{Mg}^{2+}\right]$ was adjusted to maintain appropriate cation concentrations. The combinations of the $\mathrm{CaCl}_{2}$ and $\mathrm{MgSO}_{4}$ concentration were as follows: $2 \mathrm{~mm} \mathrm{Ca}^{2+} / 1.3 \mathrm{mM} \mathrm{Mg}^{2+}, 1.75 \mathrm{mM} \mathrm{Ca}^{2+} / 3 \mathrm{mM} \mathrm{Mg}^{2+}, 1.5 \mathrm{~mm}$ $\mathrm{Ca}^{2+} / 3 \mathrm{mM} \mathrm{Mg}^{2+}, 1.25 \mathrm{~mm} \mathrm{Ca}^{2+} / 4 \mathrm{mM} \mathrm{Mg}^{2+}, 1 \mathrm{mM} \mathrm{Ca}^{2+} / 5 \mathrm{~mm} \mathrm{Mg}^{2+}$, $0.75 \mathrm{~mm} \mathrm{Ca}^{2+} / 5 \mathrm{~mm} \mathrm{Mg}^{2+}$, and $0.5 \mathrm{~mm} \mathrm{Ca}^{2+} / 5 \mathrm{~mm} \mathrm{Mg}^{2+}$.

Data were accepted and analyzed only when neurons have an input resistance $>300 \mathrm{M} \Omega$, and the synaptic response was stable with no sign of drift for at least $10 \mathrm{~min}$ before any treatment. EPSC amplitudes were defined as the mean current during a fixed 3-4 ms window at the peak of the EPSC minus the mean current during a similar window immediately before the stimulus artifact. All summary data are presented as mean \pm SEM. The Student's $t$ test was used to determine statistical significance, except where otherwise specified. A two-way ANOVA was used to compare the PP ratios and calcium-dependent release. Differences were considered significant if $p<0.05$.

Animals and genotyping. Barrelless mice were discovered as a spontaneous mutation in a line from the ICR stock at Universite de Lausanne (Van der Loos et al., 1986). Barrelless mice of the 10th backcross generation of the incipient C57BL/6-Adcy $1^{b r l}$ congenic inbred strain were used in these studies. For all of the electrophysiological experiments in this study, control (ctrl) animals were the wild-type (wt) and heterozygous (het) littermates of barrelless mice with the same genetic background. No significant differences between wt and het animals were detected, and thus for most of the data comparisons, the data points from wt and het animals were lumped together as the control group. The loss-of-function mutants of RIM $1 \alpha$ and synapsin I/II were generated in Dr. T. C. Südhof's laboratory (Rosahl et al., 1995; Castillo et al., 2002). Genotypes of these mice were determined as described previously (Rosahl et al., 1995; Castillo et al., 2002; Lu et al., 2003). Animals were treated in compliance with the United States Department of Health and Human Services and Baylor College of Medicine guidelines.

Immunoblotting. Somatosensory cortices were isolated from postnatal day 4 (P4) to P11 mice and homogenized in homogenization buffer consisting of $0.32 \mathrm{~m}$ sucrose, $10 \mathrm{~mm}$ HEPES, $\mathrm{pH} 7.4$, with protease and phosphatase inhibitor mixture (Sigma, St. Louis, MO). Total tissue homogenates were prepared as described previously (Lu et al., 2003). Twenty to $30 \mu \mathrm{g}$ of total protein were loaded onto $5-20 \%$ gradient SDSPAGE gels and electrophoretically transferred to nitrocellulose membranes (Bio-Rad, Hercules, CA). Primary antibody against the protein in question was applied, and the signals were detected with HRPconjugated secondary antibodies. The immunoreactivity was quantified with ECL (Amersham Biosciences, Piscataway, NJ) and densitometric quantification with NIH Image software (Scion, Frederick, MD). A paired $t$ test was used for most of the immunoblotting studies.

Histology. The cytochrome oxidase (CO) and Nissl staining of tangential sections of somatosensory cortex were conducted as described previously ( $\mathrm{Lu}$ et al., 2001). Briefly, a fixed, flattened cortex from $4 \%$ paraformaldehyde-perfused brains (P7 to adult) were sectioned tangentially (parallel to layer IV) with a Leica (Nussloch, Germany) Vibratome to 100 or $50 \mu \mathrm{m}$ thickness and placed in PBS. For CO staining, $100 \mu \mathrm{m}$ tangential slices were placed in CO reaction solution ( $5 \mathrm{mg}$ of diaminobenzidine, $5 \mathrm{mg}$ of cytochrome $c, 0.4 \mathrm{~g}$ of sucrose in $10 \mathrm{ml}$ of PBS, pH 7.4) for $4-18 \mathrm{~h}$ at room temperature. After staining, slices were rinsed with PBS and coverslipped with Fluoromount-G (EMS, Hatfield, PA). For Nissl staining, serial 50- $\mu$ m-thick tangential sections were mounted on Superfrost-plus slides (Fisher Scientific, Hampton, NH). After drying, the entire series of sections throughout the cortical depth were stained with cresyl violet solutions. Sections were rinsed, dehydrated in graded alcohols to xylene, and then coverslipped with xylene-based mounting medium (Cytoseal; Richard-Allen Scientific, Kalamazoo, MI). 
Antibodies. Primary antibodies were as follows: synapsin (Synaptic Systems, Göttingen, Germany), synapsin phosphorylation sitespecific antibodies (Jovanovic et al., 2001), RIMs (BD Biosciences, San Diego, CA), p-RIM(PKA) (Lonart et al., 2003), p-rabphilin and rabphilin (Lonart et al., 2001), and $\beta$-actin (Sigma). Secondary antibodies were as follows: goat anti-mouse IgG-Cy3, I-125 mouse IgG, and rabbit IgG were obtained from Amersham Biosciences; rabbit IgG Alexa 488 was obtained from Invitrogen (Eugene, OR), and mouse IgG-HRP and rabbit-IgG-HRP were obtained from Pierce (Rockford, IL).

Model. We simulate a single postsynaptic neuron that receives input from 30 thalamic afferents from two whiskers (see Fig. 7A): the primary whisker $(\mathrm{PW})$ and an adjacent whisker (AW). Barrel formation in this case corresponds to the evolution of the simulation such that afferents from the AW are eliminated. Because we are interested in discovering a situation in which this segregation fails, we initially bias the competition in favor of the PW with 20 initial contacts to the 10 contacts from the AW, so that segregation failing in this case is likely representative.

Although early postnatal thalamic activity in vivo has not been directly measured, much is known about adult thalamic activity (Simons and Carvell, 1989). Because thalamic development generally precedes cortical development, we assume thalamic activity during cortical barrel development is similar to the adult and is comprised of both isolated action potentials and bursts stimulated by vibrissa movement. Thalamic afferents fire isolated spikes with uniform probability at a rate of $8 \mathrm{~Hz}$. Bursts involving all afferents of one whisker occur randomly at a rate of $0.05 \mathrm{~Hz}$. During a burst, afferents fire a spike within $5 \mathrm{~ms}$ of burst onset and then randomly at a rate of $36 \mathrm{~Hz}$ for 100 ms.

To simulate synaptic depression, we use synapses with several active zones $\left(N_{\mathrm{AZ}}=10\right)$. Each active zone has a single vesicle, which it releases with probability $P_{\mathrm{r}}$ during a presynaptic action potential. Vesicles are replenished a time $T_{\mathrm{R}}=100 \mathrm{~ms}$ after release, and a time $T_{\mathrm{B}}$ is chosen so that a maximum of one vesicle per active zone releases during a burst. With these assumptions, the probability of release is simply related to the paired-pulse (PP) ratio (PPR): $P P R=1-\mathrm{P}_{\mathrm{r}}$.

We assume that thalamic activity causes some form of feedforward inhibition, likely mediated through intracortical pathways, to limit cortical neuronal response to thalamic input to one or two action potentials. In the adult, feedforward inhibition is prominent during both whisker movement and direct electrical stimulation in the thalamus and results in single-spike cortical response despite bursting thalamic input (Pinto et al., 2003). For simplicity, we assume that feedforward IPSPs occur regardless of whether a given active zone releases, with a $10 \mathrm{~ms}$ delay. EPSPs and IPSPs are assumed to be uniform over their duration, with EPSPs lasting $T_{\mathrm{E}}=10 \mathrm{~ms}$ and IPSPs lasting $T_{\mathrm{I}}=50 \mathrm{~ms}$. The size of EPSPs in a given time step of length $\Delta t$ is $W_{\text {syn }}(i) \times\left(\Delta t / T_{\mathrm{E}}\right)$, where $W_{\text {syn }}(i)$ is the synaptic weight of the $i$ th active zone, and the size of IPSPs is given by $w_{\text {inh }} \times\left(\Delta t / T_{\mathrm{I}}\right)$, where $w_{\text {inh }}$ is the strength of inhibitory synapses. Unlike the excitatory weight $W_{\text {syn }}(i)$, the inhibitory weight $w_{\text {inh }}$ is not plastic and is chosen such that the strength of inhibitory inputs at the beginning of the simulation is equal to 0.5 times the strength of excitatory inputs:
D

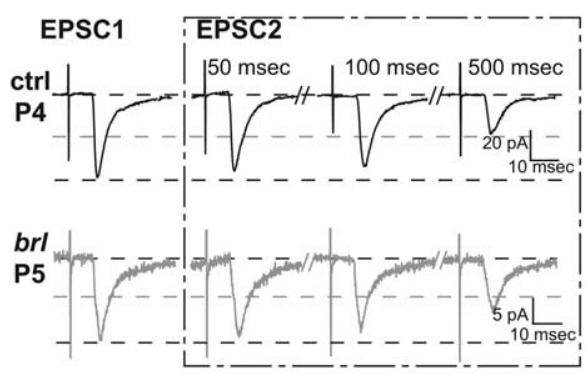

E

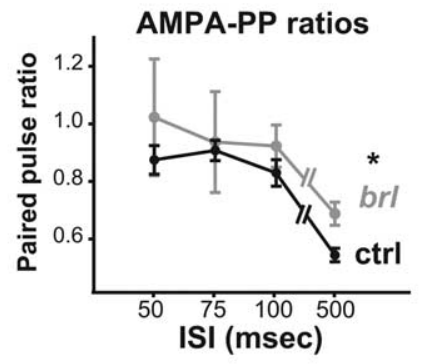

$\mathbf{F}$

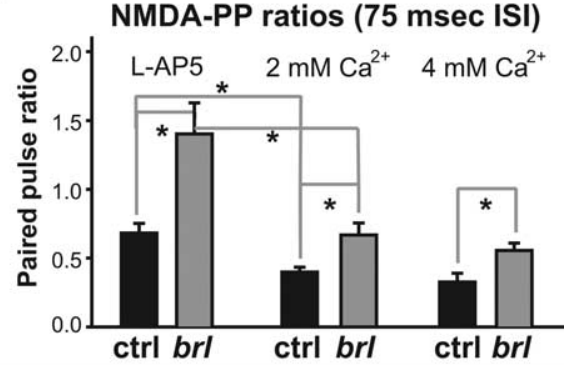

Figure 1. Paired-pulse response is defective in barrelless TC synapses. $A, B$, Example traces (average of 10 sweeps) of NMDAsion S.PP5 $0.63 \pm 0.08, n=11, P P 75,0.67 \pm 0.09, n=14, P P 100,0.61 \pm 0.05, n=13 ; P P 500,0.54 \pm 0.03, n=10.0$

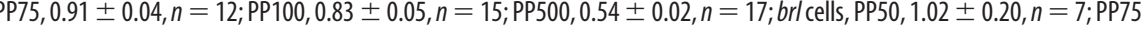
solution (P4-P8; L-AP-5: ctrl, $0.68 \pm 0.07, n=5 ;$ brl, $1.40 \pm 0.23, n=5 ; 2 \mathrm{mm:} \mathrm{ctrl,} 0.40 \pm 0.04, n=15 ;$ brl, $0.67 \pm 0.09, n=$ $14 ; 4 \mathrm{~mm}$ : ctrl, $0.33 \pm 0.06, n=6 ; b r l, 0.56 \pm 0.05, n=7)$. Asterisks indicate significant difference. Error bars represent SEM.

$w_{\text {inh }}=0.5 \mathrm{P}_{\mathrm{r}} N_{\mathrm{Az}} W_{0}$, where $W_{0}$ is the initial weight of excitatory synapses. Excitatory weights are chosen to be uniform across all synapses at the beginning of the simulation.

The cortical neuron is modeled as a simple integrate-and-fire neuron, the membrane potential of which at a time $t$ is given by $V(t)=V(t-\Delta t)$ $\exp \left(-\Delta t / \tau_{\mathrm{M}}\right)+$ (synaptic input), where $\tau_{\mathrm{M}}=100 \mathrm{~ms}$ is the membrane time constant. When the membrane potential exceeds the threshold $\theta$, the neuron fires an action potential, and $V$ is reset to zero. The threshold $\theta$ is chosen for a given simulation so that the postsynaptic firing rate is equal to the rate of all presynaptic bursts $(0.1 \mathrm{~Hz})$.

We use a spike time-dependent learning rule (see Fig. $7 B$ ) like that measured at cortical layer IV to layer II/III synapses of somatosensory cortex (Feldman, 2000). If a presynaptic vesicle release precedes a postsynaptic spike by a time $t$, the synaptic weight is strengthened by $A_{+} \exp \left(-t / \tau_{+}\right)$, and if a vesicle release follows a postsynaptic spike, the associated synaptic weight is weakened by $A_{-} \exp \left(-t / \tau_{-}\right)$. Here, $\tau_{+}=10$ $\mathrm{ms}, \tau_{-}=50 \mathrm{~ms}$, and $A_{+} / A_{-}=0.52$. The effect of the learning rule over time is mediated by the learning rate $A_{+}$, which ranged from 0.0001 to 0.001 with no change in the behavior of the simulation. Synaptic weights cannot fall below 0 , nor can they exceed a maximum value given by 


\section{A ctrl P4}

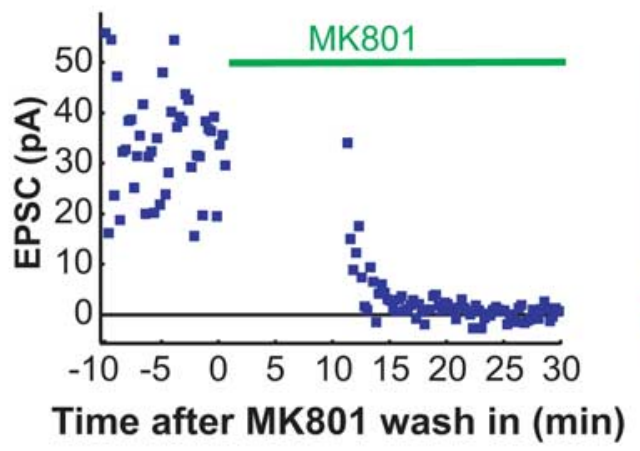

\section{B brl P4}
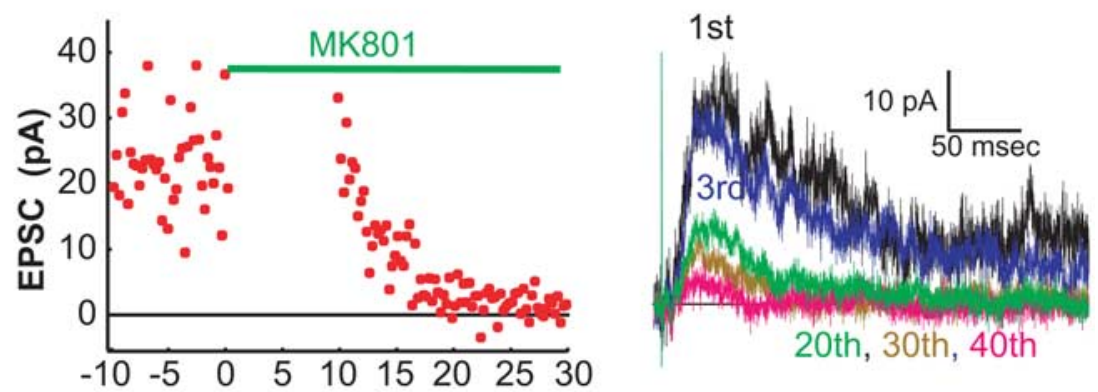

\section{Time after MK801 wash in ( $\mathrm{min})$}

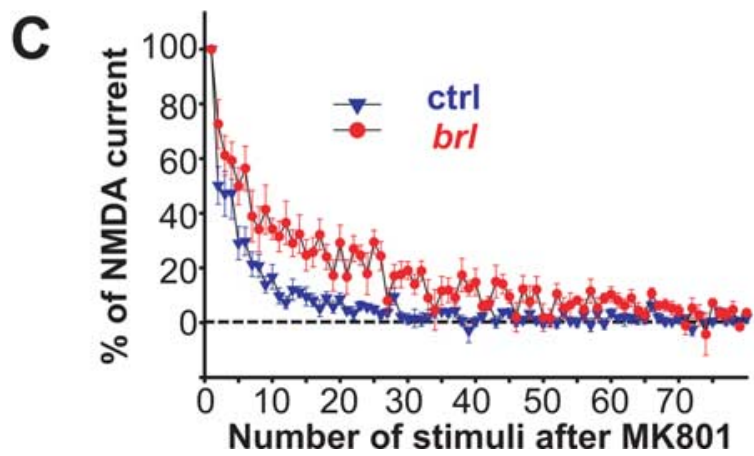

Figure 2. Barrelless TC synapses have lower release probabilities than control TC synapses. $\boldsymbol{A}, \boldsymbol{B}$, Representative examples of MK801 experiments in single ctrl $(\boldsymbol{A})$ and $b r l(\boldsymbol{B})$ P4 cells to show the progressive block of NMDA-EPSCs by $40 \mu \mathrm{m}$ MK801. The distribution of the amplitudes of NMDA-EPSCs during MK801 treatment is illustrated on the left. On the right, the first, third, 20th, 30th, and 40th traces after stimulation resumes in the presence of MK801 are shown. $A$, The amplitudes of NMDA-EPSCs decreased very rapidly in this ctrl cell. By the third stimulus, $>60 \%$ of the EPSC was inhibited by MK801. $B$, The inhibition of NMDA-EPSCs by MK801 is much slower in this brl cell. C, Summary graph of MK801 experiments for P4-P8 ctrl $(n=14)$ and brl $(n=8)$ cells. All of the values are normalized in each experiment by the amplitude of the first EPSC evoked in the presence of MK801 and averaged for each group. The inhibition kinetics, as found by fitting the decay of the NMDA-EPSC in MK801 for each cell by an exponential, was significantly different $(p<0.001)$.

potentiation and depression such that PW afferents preferentially strengthen from bursting activity and AW afferents weaken from spontaneous activity. For coincidence to lead to synaptic strengthening, it is necessary that $P_{\mathrm{r}}$ $A-P_{\mathrm{r}}\left(1-P_{\mathrm{r}}\right) B_{1}-P_{\mathrm{r}}\left(1-P_{\mathrm{r}}\right)^{2} B_{2}-P_{\mathrm{r}}(1-$ $\left.P_{\mathrm{r}}\right)^{3} B_{3}>0$, where $A, B_{1}, B_{2}$, and $B_{3}$ are approximate values from the spike time-dependent learning rule at the time of the first, second, and third spikes, respectively, and $P_{\mathrm{r}}$ is the probability of release. This condition is not met in the simulation for $P_{\mathrm{r}}<0.4$, meaning that bursts no longer lead to synaptic strengthening, upsetting the balance between potentiation and depression, and resulting in weakening of both PW and AW afferents until they can no longer drive cortical spikes.

The length of time that it takes to reach either outcome depends on the learning rate, but higher or lower values of the learning rate did not change the outcome of the simulation. As a result, the simulation time is an arbitrary number and is not labeled on the axes of Figure 7. The simulation was written in ANSI $\mathrm{c}++$, and the code is available on request.

The behavior of this simulation depends on several parameter choices that are not constrained by experiment. As a result, we verified that its qualitative behavior could be obtained for a range of such unconstrained parameter values. At the same time, we found that some general aspects of the model structure were required for our findings. In particular, it is necessary to assume some form of cortical inhibition, which prevents the cortical neuron from bursting during thalamic bursts, consistent with observations of layer IV in vivo activity at the earliest ages studied (Foeller and Feldman, 2004). This inhibition may be GABAergic, although it may well be mediated through other mechanisms early in development such as presynaptic inhibition (Rhoades et al., 1994). Without inhibition, cortical neuron spiking will always follow strong presynaptic input, meaning that bursts will always lead to strengthening, and decreasing $P_{\mathrm{r}}$ will not prevent segregation.

\section{Results}

Impaired short-term synaptic plasticity in barrelless TCAs

We first used a paired-pulse protocol to characterize neurotransmitter release properties of TC synapses in developing barrelless and control neurons. Pairedpulse (PP) ratios are a standard measure of presynaptic function that is typically in-

$\theta /\left(2 \mathrm{P}_{\mathrm{r}} N_{\mathrm{AZ}}\right)$, such that, at their strongest, an average of two simultaneously spiking afferents are needed to evoke a postsynaptic spike. For the simulations shown in Figure $7 F$, PPR and the strength of LTD $\left(A_{-}\right)$ were held constant and the long-term potentiation (LTP)/long-term depression (LTD) ratio was varied as shown.

The simulation was run at a time step of $\Delta t=1 \mathrm{~ms}$, which was sufficiently small relative to the other simulation time scales (the learning rule and burst dynamics). The simulation ran until either the AW weights went to 0 (segregation) or the layer IV neuron stopped firing. For sufficiently high release probability $\left(P_{\mathrm{r}}>0.4\right.$, or PPR $\left.<0.6\right)$, PW afferents strengthened and AW afferents weakened, meaning the simulation segregated (see Fig. $7 C-E$ ). Segregation occurs as a result of a balance of versely related to the probability $\left(P_{\mathrm{r}}\right)$ of neurotransmitter release (Zucker and Regehr, 2002). PP ratios are determined by measuring the relative response amplitude to two closely spaced stimuli. Synapses with high $P_{\mathrm{r}}$ regularly show paired-pulse depression (PPD), whereas synapses with low $P_{\mathrm{r}}$ show paired-pulse facilitation. TC synapses are glutamatergic and contain a mixture of AMPARs, kainate receptors, and NMDA receptors (NMDARs) (Kidd and Isaac, 1999; Lu et al., 2001). We initially used NMDAR-mediated EPSCs to examine PP ratios at TC synapses with a range of interstimulus intervals (ISIs; 50, 75, 100, and 500 


\section{A ctrl P4}
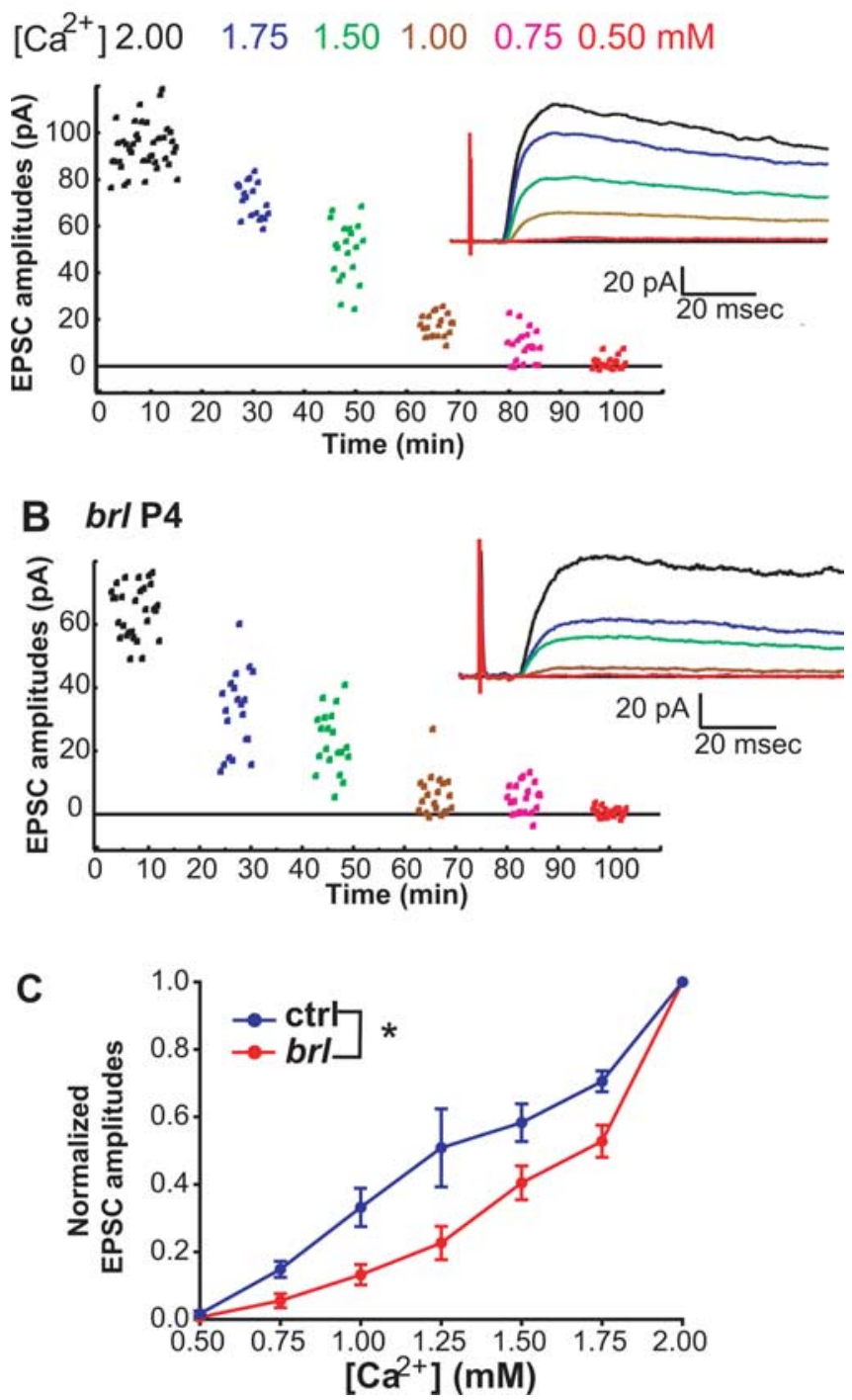

Figure 3. Calcium dependence of NMDA-EPSCS. $\boldsymbol{A}, \boldsymbol{B}$, Representative calcium-dependence experiments in single $\operatorname{ctrl}(\boldsymbol{A})$ and brl (B) P4 cells. The distributions of the amplitudes of NMDAEPSCs recorded in different external $\left[\mathrm{Ca}^{2+}\right]$ are illustrated on the left, whereas the average traces (average of 10 sweeps) are shown on the right. The amplitudes of NMDA-EPSCs decreased gradually in this ctrl cell after the reduction of external $\left[\mathrm{Ca}^{2+}\right]$, whereas the reduction of NMDA-EPSCS occurred rather quickly in this brl cell. C, The dose-response curves of the normalized EPSC amplitudes to different external $\left[\mathrm{Ca}^{2+}\right]$ for ctrl and br/ synapses. To standardize the responses between cells, the average amplitudes of NMDA-EPSCs at each $\left[\mathrm{Ca}^{2+}\right]$ were normalized to the average amplitude at $2 \mathrm{~mm}\left[\mathrm{Ca}^{2+}\right]$. The normalized amplitudes for ctrl are $0.02 \pm 0.0$ for $0.5 \mathrm{~mm}(n=5), 0.15 \pm 0.02$ for $0.75 \mathrm{~mm}(n=8), 0.33 \pm 0.06$ for $1 \mathrm{~mm}(n=8)$, $0.51 \pm 0.12$ for $1.25 \mathrm{~mm}(n=5), 0.58 \pm 0.06$ for $1.5 \mathrm{~mm}(n=6)$, and $0.71 \pm 0.03$ for $1.75 \mathrm{~mm}$ $(n=5)$. The normalized amplitudes for brl are $0.0 \pm 0.0$ for $0.5 \mathrm{~mm}(n=2), 0.06 \pm 0.02$ for $0.75 \mathrm{~mm}(n=2), 0.13 \pm 0.03$ for $1 \mathrm{~mm}(n=5), 0.23 \pm 0.05$ for $1.25 \mathrm{~mm}(n=4), 0.40 \pm 0.05$ for $1.5 \mathrm{~mm}(n=5)$, and $0.53 \pm 0.05$ for $1.75 \mathrm{~mm}(n=4)$. The asterisk indicates significant difference.

ms). In control cells, paired stimuli produced strong PPD (Fig. $1 A, C$ ), consistent with the high $P_{\mathrm{r}}$ found at TC synapses (Gil et al., 1999; Yanagisawa et al., 2004). Significantly less depression was evoked in barrelless TC synapses at all ISIs tested (Fig. $1 B, C$ ) $(p<0.001$ for difference between $b r l$ and ctrl across the range of ISIs; two-way ANOVA; $p<0.001$ for difference between $b r l$ and ctrl at 50 and $75 \mathrm{~ms}$ ISIs and $p<0.05$ for difference between $b r l$ and ctrl at 100 and $500 \mathrm{~ms}$ ISIs using a pairwise multiple comparison or Tukey's test).
We also measured AMPA-PP ratios in control and barrelless TC synapses (Fig. $1 D, E$ ). As with NMDA-PP ratios, paired stimuli induced PPD in both control and barrelless neurons. AMPA-PP ratios were more variable in barrelless than in control neurons, probably because AMPA currents themselves are small in barrelless mutants (Lu et al., 2003), increasing their variability (pharmacologically reducing the amplitude of AMPA currents in control neurons leads to similar variability) (supplemental Fig. 1, available at www.jneurosci.org as supplemental material). Nonetheless, PP depression was significantly less in barrelless TC synapses compared with control across the range of ISIs (Fig. $1 D, E)(p<0.01$ for difference between $b r l$ and ctrl across the range of ISIs; two-way ANOVA; no statistically significant difference for any one ISI using a pairwise multiple comparison or Tukey's test).

We noted, as have others (Yanagisawa et al., 2004), that PP ratios for AMPAR-EPSCs were larger than for NMDAR-EPSCs at TC synapses. This suggests that postsynaptic mechanisms, such as NMDAR saturation (Chen et al., 2002), may contribute to short-term synaptic plasticity. To examine this, NMDA-PP ratios were measured in the presence of a low-affinity antagonist to NMDARs, L-AP-5 (800 $\mu \mathrm{M})$. The substantial increase in NMDA-PP ratio with L-AP-5 demonstrates that NMDAR saturation normally contributes to short-term plasticity (Fig. $1 F$ ) (supplemental Fig. 2, available at www.jneurosci.org as supplemental material). However, even in the presence of $\mathrm{L}-\mathrm{AP}-5$, barrelless $\mathrm{PP}$ ratios remain significantly higher than in control neurons $(p<0.02)$, demonstrating that differences in NMDAR saturation are not causing the observed differences in short-term plasticity between barrelless and control neurons. There are many mechanisms that could contribute to the observed difference in PP ratios between barrelless and control TC synapses, including differences in the calcium-binding affinity of calcium sensors, calcium buffers, or the distance between calcium channels and neurotransmitter release machinery. We used high $\mathrm{Ca}^{2+}$ (4 mM) Ringer's solution to maximize $P_{\mathrm{r}}$ at TC synapses and to saturate calcium sensors. Barrelless PP ratios measured in high $\mathrm{Ca}^{2+}$ Ringer's solution are still significantly elevated relative to control neurons $(p=0.02)$, despite the slight reduction in overall $\mathrm{PP}$ ratio. The insignificant reduction in $\mathrm{PP}$ ratio in high $\mathrm{Ca}^{2+}$ Ringer's solution in both control $(p=0.09)$ and barrelless neurons $(p=0.25)$ also suggests that $P_{\mathrm{r}}$ for TCAs is close to maximal in normal $(2 \mathrm{mM}) \mathrm{Ca}^{2+}$ Ringer's solution. This implies that the short-term plasticity deficits observed in barrelless TCAs are not attributable to intrinsic defects in neurotransmitter release machinery in the absence of $\mathrm{ACl}$ function. Together, the increased PP ratios in barrelless, detected with both AMPA- and NMDA-EPSCs, suggests that short-term synaptic plasticity at barrelless TCAs is defective and the probability of neurotransmitter release $\left(P_{\mathrm{r}}\right)$ is reduced.

\section{Slow block of NMDA-EPSCs by MK801 in barrelless TC synapses}

The rate at which the amplitude of NMDAR-mediated EPSCs are attenuated by MK801 during repetitive stimulation is an indirect indication of presynaptic release probability (Hessler et al., 1993; Rosenmund et al., 1993; Manabe and Nicoll, 1994). This method depends on the fact that NMDA receptors must first be opened before they can be blocked by MK801, and the blockade is essentially irreversible. NMDA-EPSC amplitudes decrease progressively with repeated stimuli in the presence of MK801, and the rate of NMDA channel blockade varies inversely with the probability of vesicular release. NMDA-EPSCs decay quickly in the presence of MK801 in control neurons (Fig. 2A,C), indicating that $P_{\mathrm{r}}$ is high at TC synapses. Blockade by MK801 in barrelless neurons is much slower, and substantial residual response was detected even after 40 stimuli (Fig. 
A

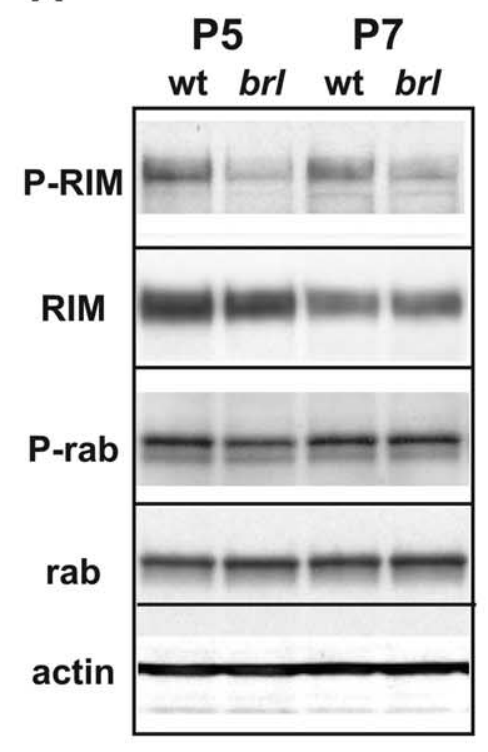

B
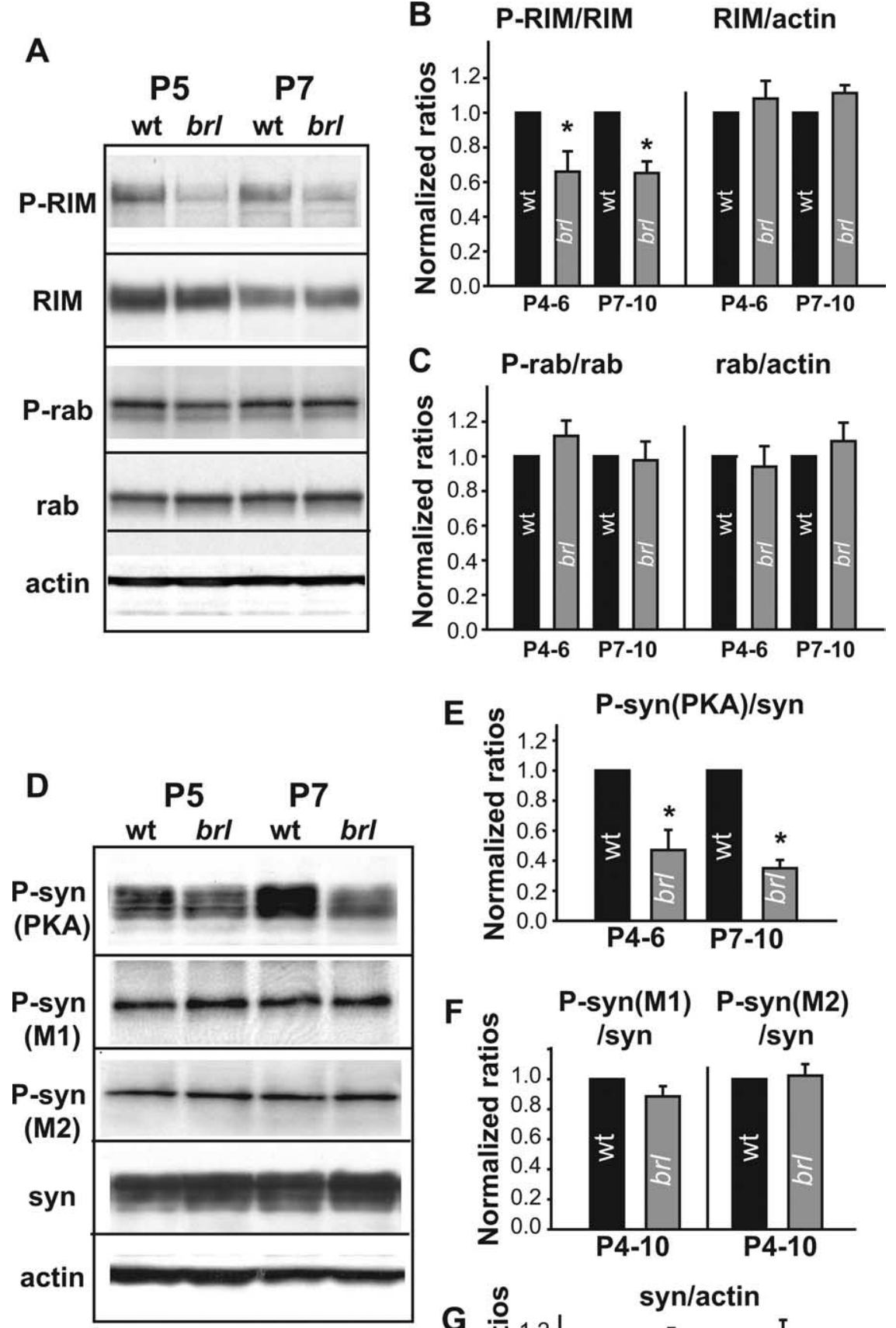
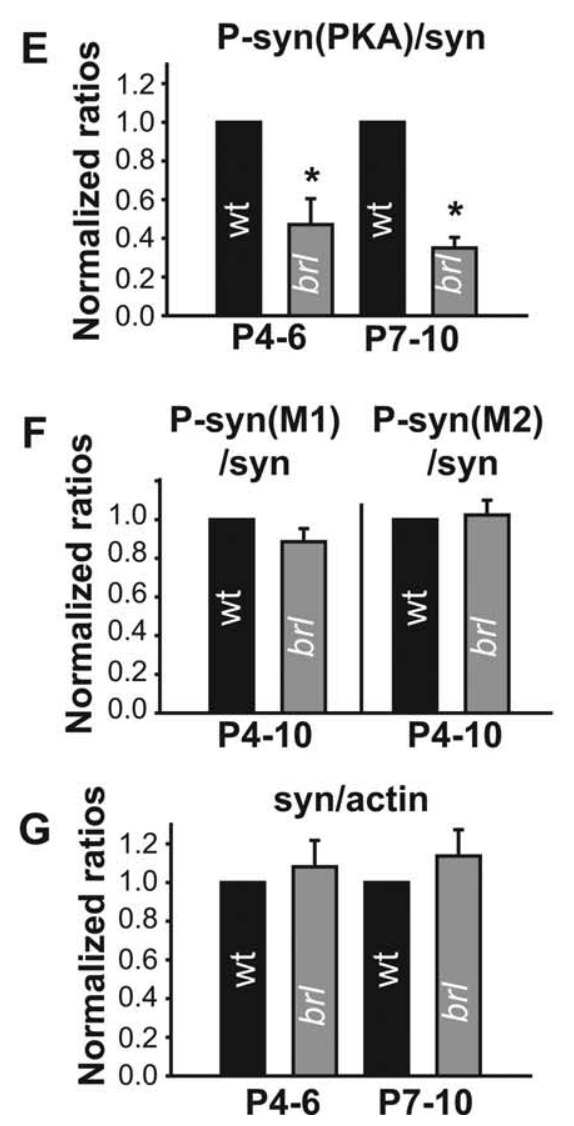

Figure 4. RIMs and synapsins, but not rabphilin, are putative AC1 targets. $A$, Western blots show that the amount of PKAphosphorylated RIM (P-RIM) is greatly reduced in brl somatosensory cortex but not the amount of total RIM, PKA phosphorylated rabphilin (P-rab), or total rabphilin (rab). Actin immunoreactivity was used as a loading control. $B$, Histogram of the normalized ratios of P-RIM/RIM and RIM/actin as fractions of wt values (normalized in pairs). Normalized $b r / P$-RIM/RIM levels are as follows: P4-P6group, $0.34 \pm 0.04$, four pairs; $P 7-P 10$ group, $0.35 \pm 0.07,13$ pairs. Normalized br/ RIM/actin levels are as follows: P4-P7 mice, $1.08 \pm 0.10$, four pairs; P7-P10 mice, $1.11 \pm 0.05$, eight pairs. C, Histogram of the normalized ratios of P-rab/rab and $\mathrm{rab} / \mathrm{actin}$. Normalized br/ P-rab/rab levels are as follows: $1.12 \pm 0.09$ for four pairs of $\mathrm{P} 4-\mathrm{P} 6$ and $0.98 \pm 0.11$ for four pairs of P7-P10 age groups. Normalized brl rab/actin levels are as follows: $0.94 \pm 0.12$ for four pairs of P4 -P6 and $1.09 \pm 0.11$ for four pairs of P7-P10. D, Western blots showing a decrease in the amount of PKA-phosphorylated synapsin [P-syn(PKA)] but not the amount of total synapsin (syn) or MAPK-phosphorylated synapsin [P-syn(M1) or P-syn(M2)]. E-G, Histograms summarizing the
$2 B, C)$. Fitting the decay of the NMDA current in MK801 by an exponential reflects this difference, with a time constant of $19.37 \pm 3.4$ stimuli in barrelless neurons $(n=8)$ versus $4.64 \pm 0.8$ stimuli in control neurons $(n=14 ; p<0.001$; Mann-Whitney rank sum test). This difference in MK801 blockade is not a result of aberrant NMDAR function, because both the subunit composition of NMDARs (Lu et al., 2003) and the decay kinetics of NMDA currents (supplemental Fig. 3, available at www.jneurosci.org as supplemental material) are normal in barrelless synapses. The difference in the rate of NMDA-EPSC blockade by MK801 between control and barrelless neurons as well as the difference in pairedpulse ratio in barrelless neurons both suggest that $P_{\mathrm{r}}$ is lower in barrelless TC synapses.

Calcium-dependent release is different in barrelless $\mathrm{TC}$ synapses

Another measure of presynaptic function is the sensitivity of release to intracellular calcium concentration $\left(\left[\mathrm{Ca}^{2+}\right]\right)$ (Wolfel and Schneggenburger, 2003). To test whether a change in $\mathrm{Ca}^{2+}$ sensitivity can account for, at least in part, the reduced $P_{\mathrm{r}}$ in barrelless TC synapses, we examined the response in $\mathrm{P} 4-\mathrm{P} 6$ control and barrelless neurons to a change in extracellular $\left[\mathrm{Ca}^{2+}\right]$ in the range of $0.5-2 \mathrm{mM}$. At these relatively low concentrations, the intracellular $\left[\mathrm{Ca}^{2+}\right]$ that drives vesicle fusion is likely to have a linear relationship with the extracellular $\left[\mathrm{Ca}^{2+}\right]$ (Dodge and Rahamimoff, 1967; Reid et al., 1998). We measured NMDA-EPSC amplitudes as a function of extracellular $\left[\mathrm{Ca}^{2+}\right]$ and quantitatively compared responses in control and barrelless neurons (Fig. 3). As expected, evoked EPSCs were significantly reduced when the external $\left[\mathrm{Ca}^{2+}\right]$ was decreased (Fig. $3 A, B$ ). However, the relationship between EPSC amplitude and $\left[\mathrm{Ca}^{2+}\right]$ was very different in control and barrelless synapses $(p<0.001$ by ANOVA) (Fig. 3C), with barrelless neurons requiring higher $\left[\mathrm{Ca}^{2+}\right]$ to reach comparable evoked amplitudes. Generally, the relationship between EPSC amplitude and extracellular $\left[\mathrm{Ca}^{2+}\right]$ is differ-

normalized ratios of P-syn(PKA)/syn (E), P-syn(M1)/syn and P-syn(M2)/syn $(\boldsymbol{F})$, and syn/actin (G) as fractions of wildtype values. Normalized $b r / P$-syn (PKA)/syn levels are as follows: $0.47 \pm 0.13$ for six pairs of $P 4-P 6$ group and $0.35 \pm$ 0.06 for eight pairs of P7-P11 group. P-syn(M1)/syn is $0.89 \pm 0.07$ for eight pairs; $P$-syn(M2)/syn is $1.02 \pm 0.08$ for eight pairs; syn/actin is $1.08 \pm 0.14$ for eight pairs of $P 4-P 6$ mice and $1.14 \pm 0.14$ for eight pairs of P7-P10 mice. Asterisks indicate significant difference. 
ent in low $P_{\mathrm{r}}$ synapses and high $P_{\mathrm{r}}$ terminals (Rozov et al., 2001), so the reduced sensitivity to $\left[\mathrm{Ca}^{2+}\right]$ in barrelless TC synapses likely reflects reduced $P_{r}$. These data are consistent with our findings from the paired-pulse and MK801 experiments, all of which indicate functional deficits in the neurotransmitter release machinery in barrelless TCAs.

\section{Synapsin and RIM proteins are putative} AC1 targets in barrel cortex

Functional interactions between synaptic vesicle proteins and active zone proteins in the neurotransmitter release apparatus are modulated by neural activity through cAMP-dependent protein kinase A (PKA) phosphorylation (Lonart, 2002). A prominent PKA target in the presynaptic release apparatus is the RIM family of active zone proteins. RIM $1 \alpha$ is directly phosphorylated by PKA, and the N-terminal PKA site (Ser-413) on RIM1 $\alpha$ is required for cerebellar parallel fiber LTP (Lonart et al., 2003). We examined the degree of PKA phosphorylation of RIM using the N-terminal PKA site-specific antibody [PKA-phosphorylated RIM (P-RIM)] (Fig. 4A,B). Tissue homogenates were prepared from the somatosensory cortex of $\mathrm{P} 4-$ P10 wild-type and barrelless mice. A decrease in the normalized $\mathrm{P}-\mathrm{RIM} / \mathrm{RIM}$ level was already evident in $\mathrm{P} 4-\mathrm{P} 6$ barrelless somatosensory cortex $(p<0.01)$ and was also obvious in P7-P10 barrelless mice $(p<0.01)$. There was no detectable difference in total RIM levels. We also examined the degree of PKA phosphorylation on rabphilin, another presynaptic PKA target (Lonart and Sudhof, 1998, 2001; Schluter et al., 1999). No difference was detected in the degree of PKA phosphorylation on rabphilin or in the total amount of rabphilin (Fig. $4 A, C$ ).

Synapsins are integral synaptic vesicle membrane proteins that are also major phosphoproteins in the neurotransmitter release machinery (Czernik et al., 1987; Greengard, 1987; Hilfiker et al., 1999; Hosaka et al., 1999; Jovanovic et al., 2001; Wang and Sudhof, 2003). Synapsins are phosphorylated by several kinases, including PKA and MAPK (mitogen-activated protein kinase). PKA phosphorylation on synapsins is implicated in the regulation of neurotransmitter release through synaptic vesicle mobilization (Chi et al., 2001). There are three known synapsin isoforms (Feng et al., 2002), and studies with synapsin I/II double knock-out $(\mathrm{KO})$ mice suggest these proteins are required to maintain a normal number of synaptic vesicles and to regulate short-term synaptic plasticity (Rosahl et al., 1993, 1995; Li et al., 1995). Using a PKA site-specific antibody that recognizes PKAphosphorylated synapsin (Jovanovic et al., 2001), we found that the fraction of PKA-phosphorylated synapsin relative to total synapsin is significantly reduced $(p<0.01)$ in barrelless somatosensory cortex (Fig. $4 D, E$ ). We also examined the quantity of MAPK-phosphorylated synapsin with two MAPK site-specific antibodies. No detectable difference was observed for the abundance of MAPK-phosphorylated synapsin or total synapsin between wild-type and barrelless synapses (Fig. $4 D, F, G$ ). In summary, we identified synapsins and RIMs, proteins involved in the regulation of neurotransmitter release, as putative $\mathrm{AC} 1$ targets in mouse barrel cortex.

\section{Barrel map deficits in RIM1 $\alpha$ KO mice}

To clarify the role of RIMs and synapsins in barrel development, we examined the organization of barrel maps in RIM $1 \alpha \mathrm{KO}$ and synapsin I/II double KO mice with $\mathrm{CO}$ and Nissl histochemistry (Fig. 5), standard procedures for revealing whisker-related patterns at the subcortical and cortical levels of the rodent trigeminal pathway (Killackey and Leshin, 1975). In young (P8-P21) RIM $1 \alpha \mathrm{KO}$ mice, $\mathrm{CO}$ barrels corresponding to the small tactile hairs on the snout were absent or indistinct (Fig. $5 B)(n=10)$, whereas $\mathrm{CO}$ barrels for the large whiskers remained intact. Clear $\mathrm{CO}$ patterns for all of the barrels were observed in paired littermate controls (Fig. 5A) $(n=10)$. In adult RIM1 $\alpha$ KO mice (3-6 months of age; $n=4)$, small $\mathrm{CO}$ barrel boundaries were again indistinct (Fig. 5D,F), in contrast to littermate controls (Fig. 5C) $(n=4)$ and synapsin I/II double KO mice (Fig. $5 E)(n=2)$. We also examined layer IV barrel cytoarchitecture with Nissl-stained serial sections from RIM1 $\alpha$ KO mice and paired littermate controls. Distinct barrel walls throughout the barrel field were always evident in control mice (Fig. $5 I)(n=8)$. In contrast, a rather uniform distribution of layer IV neurons was observed in the somatosensory cortices of RIM1 $\alpha \mathrm{KO}$ mice (Fig. 5J) $(n=8)$, except for a few large barrels with a rudimentary barrel pattern. No obvious abnormality in the pattern of thalamic barreloids was found in RIM $1 \alpha \mathrm{KO}$ mice (Fig. $5 G, H$ ) ( $n=3$ pairs). A representative series of Nissl-stained sections through layer IV from a pair of control (Fig. 6A) and RIM1 $\alpha$ KO mice (Fig. $6 B$ ) at P24 confirms the barrel cytoarchitectural deficits in RIM1 $\alpha \mathrm{KO}$ mice. These data strongly support the notion that RIM1 $\alpha$ is an AC1 target in cortical barrel map formation.

In hippocampal neurons, RIM1 $\alpha$ mutants show an increased $\mathrm{PP}$ ratio and slower block by MK801, reflecting functional deficits in presynaptic release efficacy (Schoch et al., 2002; Calakos et al., 2004). We therefore investigated whether RIM $1 \alpha$ mediates, at least in part, AC1 modulation of presynaptic release efficacy at TC synapses during barrel map development. Indeed, PP ratios for both NMDAR-EPSCs and AMPAR-EPSCs were significantly 
A
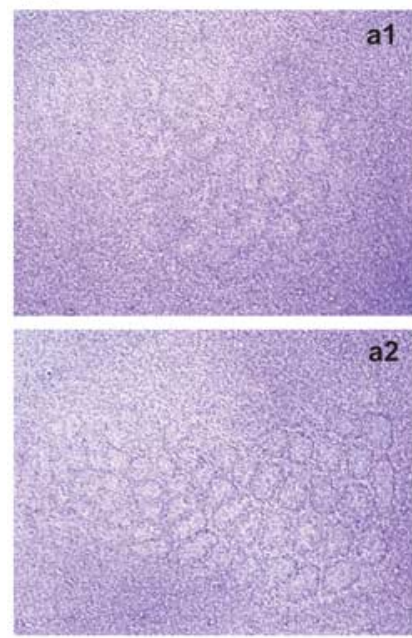

a3
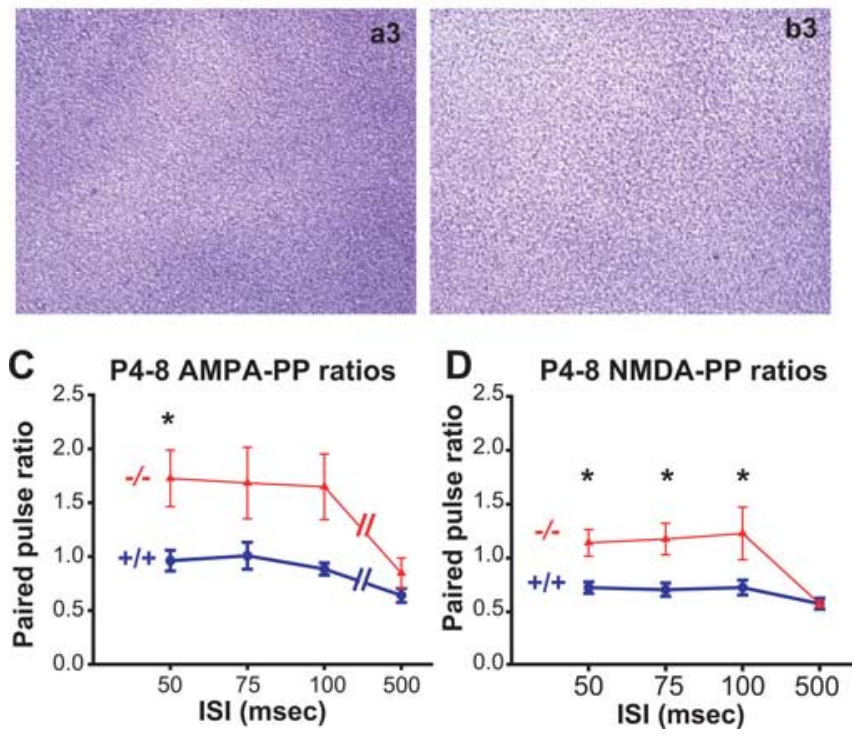

Figure 6. RIM1 $\alpha$ is critical for short-term plasticity in TC synapses. $\boldsymbol{A}, \boldsymbol{B}$, Series of tangential Nissl sections from representative ctrl $(\boldsymbol{A})$ and RIM1 $\alpha^{-I-}(\boldsymbol{B})$ mice. $\boldsymbol{a} 2$ is the ctrl section with a clear barrel pattern; $\boldsymbol{a} \mathbf{1}$ and $\boldsymbol{a} \mathbf{3}$ are the adjacent sections above and below $\boldsymbol{a} \mathbf{2} . \boldsymbol{b} \mathbf{1}-\boldsymbol{b} \mathbf{3}$ are a similar series of Nissl sections from a littermate RIM1 $\alpha^{-I-}$ mouse, with little detectable barrel pattern. C, Summary data for AMPA-EPSCPP ratios (PP ratios for ctrl cells: PP50,0.96 $\pm 0.1, n=14 ;$; PP75, 1.01 $\pm 0.12, n=14$; PP100, $0.88 \pm 0.06, n=14 ; \mathrm{PP} 500,0.64 \pm 0.06, n=14 ; \mathrm{RIM} 1 \alpha^{-l-}$ cells: PP50, $1.73 \pm 0.26$, $n=5 ; P P 75,1.68 \pm 0.33, n=5 ; P P 100,1.65 \pm 0.30, n=5 ; P P 500,0.84 \pm 0.14, n=5) . \boldsymbol{D}$, Summary of P4-P7 NMDA-PP ratios with various ISIs. The ctrl PP ratios are as follows: PP50, $0.72 \pm$ $0.05, n=12 ; \mathrm{PP75}, 0.71 \pm 0.06, n=12 ; \mathrm{PP} 100,0.73 \pm 0.07, n=12 ; \mathrm{PP} 500,0.58 \pm 0.05, n=12$. The RIM1 $\alpha^{-1-}$ PP ratios are as follows: PP50, $1.14 \pm 0.12, n=5 ; \mathrm{PP75}, 1.18 \pm 0.15, n=5$; $\mathrm{PP} 100,1.23 \pm 0.24, n=5 ; \mathrm{PP} 500,0.57 \pm 0.03, n=5$. PP ratios were significantly higher in RIM1 $\alpha^{-l-}$ cells for $50-100 \mathrm{~ms}$ ISI. Asterisks indicate significant difference.

higher in RIM $1 \alpha \mathrm{KO}$ TC synapses than littermate control cells for 50, 75, and $100 \mathrm{~ms}$ ISIs (Fig. 6C,D). The degree of depression triggered by 500 ms ISIs in RIM1 $\alpha$ KO synapses was not different from control neurons for both NMDA- and AMPA-EPSCs. This is similar to what was observed in hippocampal synapses (Schoch et al., 2002; Calakos et al., 2004) but different from what was observed at barrelless TC synapses. This suggests that PPD triggered by long ISIs at TC synapses is mediated through an AC1dependent pathway that is independent of $\operatorname{RIM} 1 \alpha$. The barrel cytoarchitecture and TCA neurotransmitter release deficits in RIM $1 \alpha$ mutants together strongly suggest that efficient presynaptic function plays an important role in cortical barrel map development.

\section{Decreased presynaptic release probability can disrupt barrel segregation}

To demonstrate how the observed deficits in synaptic function in barrelless mice could disrupt barrel development, we constructed a model for neural activity-dependent (Hebbian) barrel map formation and tested the effects of reducing neurotransmitter release efficacy on barrel segregation (Fig. 7) (see Materials and Methods, Model). The activity-dependent development of neural circuits is thought to be driven by synaptic learning rules that translate patterns of neural activity in presynaptic and postsynaptic neurons into changes in synaptic strength (Crair and Malenka, 1995; Katz and Shatz, 1996). We used a spike time-dependent learning rule (Fig. 7B) (Abbott and Nelson, 2000; Dan and Poo, 2004) similar to that known to drive synaptic development in layer IV to layer II/III synapses in somatosensory cortex (Feldman, 2000) and retinotopic map development at the retinotectal synapse (Zhang et al., 1998).

With a spike timing-dependent learning rule (Fig. $7 B$ ), strengthening of the synapse occurs when an EPSC precedes a cortical action potential (spike), and weakening occurs when an EPSC follows the cortical spike. Because thalamic afferents burst while cortical neurons typically respond with isolated spikes (Simons and Carvell, 1989; Pinto et al., 2003), afferent spikes can occur before or after an evoked cortical spike, in proportions dictated by the probability of release (Fig. 7B). For high probability of release synapses, afferent spikes will typically lead cortical spikes, resulting in more LTP than LTD. Because the initially strong PW synapses evoke more cortical spikes than the AW, they are further strengthened. The stronger PW synapses also cause more cortical spikes to be uncorrelated with AW activity, resulting in more AW activity that falls into the larger LTD window. Thus, for high release probability (low PPR) (Fig. 7C), segregation occurs because of "potentiation" from afferent activity that drives cortical spikes, and "depression" from afferent activity uncorrelated with cortical spiking: PW synapses strengthen because there is more LTP than LTD, and AW afferents weaken because the ratio balances in favor of LTD.

This LTP/LTD balance is achieved only if afferent whisker stimulation, which produces bursts of thalamic activity in vivo, does not induce bursts of cortical activity; otherwise, LTP will always dominate because afferent spikes will precede most cortical spikes. It is therefore essential to include an inhibitory component in the model, which dampens cortical response to whisker stimulation to one or two spikes, consistent with observations of layer IV in vivo activity at the earliest ages studied (Foeller and Feldman, 2004). This inhibition may occur through feedforward GABAergic circuits (Foeller and Feldman, 2004), or via other developmentally regulated mechanisms, such as modulation of neurotransmitter release by monoamines (Rhoades et al., 1994).

Reducing the probability of vesicular release can also upset the balance between LTP and LTD, because afferent activity more often fails to elicit vesicular release before the postsynaptic spike (Fig. $7 B$ ) (PPR, 0.7 instead of 0.5). As a result, the afferent bursting that evokes a cortical spike will result in less strengthening, whereas the amount of weakening from uncorrelated afferent activity stays constant. This causes the weakening of both PW and AW afferents until they can no longer drive cortical spikes (Fig. 7D,E) (PP ratios $>0.6$ ). The failure to segregate for high PP ratios predicts the final state of TC synapses observed in barrelless, in which afferents do not segregate into barrels, and AMPAR-mediated currents are small. Thus, presynaptic neurotransmitter release deficits will favor LTD over LTP, disrupt segregation, and lead to weaker TC synapses.

The presynaptic deficits described here are consistent with a more general situation in which the strength of LTP is decreased relative to LTD. Directly changing the ratio of LTP relative to 
LTD in the model also prevents segregation (Fig. 7F). Our model does not specifically distinguish between the role of the presynaptic deficit described here in barrelless mice and the previously observed postsynaptic deficits in AMPAR trafficking (Lu et al., 2003), which also might affect the overall strength of LTP relative to LTD. Rather, it illustrates how interfering with either may disrupt thalamic afferent segregation and barrel formation.

\section{Discussion}

We presented evidence that barrelless (AC1) mutant mice have impaired neurotransmitter release machinery that contributes to their barrelless phenotype. With biochemical techniques, we identified RIM proteins as likely targets for AC1/PKA signaling. We further showed that RIM1 $\alpha$ mutant mice have TCA neurotransmitter release deficits and impaired barrel patterning, which confirms that interfering with presynaptic release negatively impacts neural circuit development. Finally, we used a computational model to demonstrate how inadequacies in presynaptic function will obstruct the activity-dependent process responsible for the segregation of sensory afferents. Together, our data suggest that efficient neurotransmitter release at thalamocortical synapses, which is a general feature of afferents in all sensory pathways, is important in the development of precise cortical maps.

\section{AC1 regulates presynaptic release in TC} synapses through RIMs

We found a significant reduction in the PKA

phosphorylation level of RIMs in barrelless somatosensory cortex, suggesting that $\mathrm{ACl}$ regulates presynaptic vesicular release through the phosphorylation of these proteins. Like barrelless mutants, we also found that RIM $1 \alpha$ mutant TC synapses have decreased pairedpulse depression, and others have noted in the hippocampus of RIM1 $\alpha$ mutants similar deficits in short-term plasticity and differences in the rate of synaptic blockade by MK801 (Schoch et al., 2002; Calakos et al., 2004). The barrel pattern defects in RIM1 $\alpha$ knock-out mice also strongly suggest that the AC1-mediated regulation of presynaptic function responsible for barrel development acts at least in part through RIMs. However, there are a number of ways independent of RIM proteins in which AC1 may also modulate presynaptic release. For example, PKA phosphorylation of synapsins, which is also reduced in barrelless mice, may modulate neurotransmitter release through synaptic vesicle mobilization (Chi et al., 2001), although synapsin mutants have normal barrels. Other direct PKA targets that may be responsible for the decrease in presynaptic release efficacy observed in barrelless mutants include cysteine string protein (Evans et al., 2001), SNAP25 (synaptosome-associated protein 25) (Risinger and Bennett, 1999; Hepp et al., 2002; Nagy et al., 2004), snapin (Chheda et al., 2001), and syntaphilin (Lao et al., 2000; Boczan et al., 2002). The changes in release sensitivity to $\left[\mathrm{Ca}^{2+}\right]$ we observed in barrelless mutants may also be mediated by a downstream target other then RIM, because $\left[\mathrm{Ca}^{2+}\right]$ sensitivity is unchanged in RIM1 $\alpha$ mutant mice (Calakos et al., 2004). It is also
B

B Postsynaptic spike C

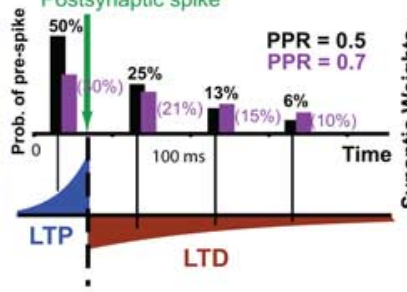

E

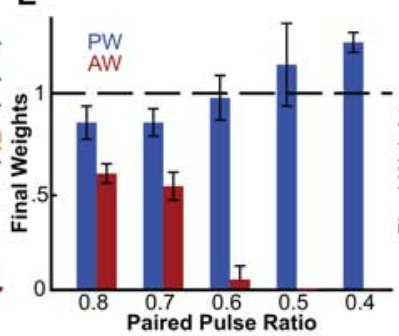

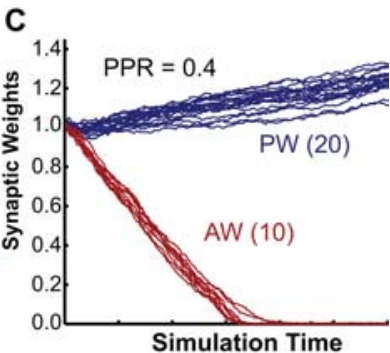

$\mathbf{F}$

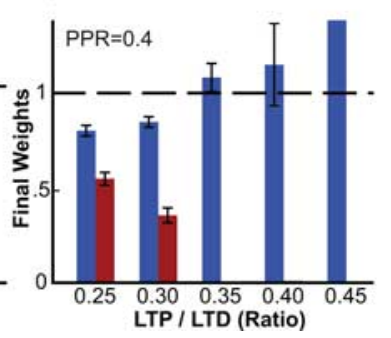

Figure 7. Model of barrel map development. $\boldsymbol{A}$, Schematic of model. Initially, 20 principal whisker afferents (PW) and 10 whisker afferents (AW) contact a layer IV neuron, reflecting the initial somatotopic bias established by molecular genetic 列 the area under the LTP curve ( $\boldsymbol{B}$; blue) divided by the area under the LTD curve ( $\boldsymbol{B}$; red)]. Changing the PPR is equivalent to directly modifying the LTP/LTD ratio, and segregation fails for LTP/LTD ratios less than $\sim 0.3$.

possible that AC1 modulates neurotransmitter release independent of PKA, because RIM1 $\alpha$ binds to cAMP-GEFII (guanine nucleotide exchange factor II) (Ozaki et al., 2000), a direct target of cAMP that is responsible for CAMP-dependent, but PKA-independent exocytosis. A detailed understanding of the signaling cascades triggered by $\mathrm{AC} 1$ that regulate neurotransmitter release will require alternative experimental approaches, possibly autaptic neuronal cultures or some other reduced preparation with greater power to assay the molecular basis for defects in neurotransmitter release. Regardless, our data clearly demonstrate a presynaptic role for $\mathrm{AC} 1$ in regulating the efficiency of vesicular release, and show that the AC1 phosphorylation target RIM1 $\alpha$ contributes to barrel map development.

\section{Barrel map deficits in RIM1 $\alpha$ mutants}

There are a handful of mutants that display barrel map deficits (Erzurumlu and Kind, 2001; Hannan et al., 2001; Lopez-Bendito and Molnar, 2003). Barrelless (AC1 KO) mice rank among the strongest phenotypes; with no hint of barrel patterning in either the thalamocortical afferent arbors or the postsynaptic neuronal cytoarchitecture. It is more common, as in RIM $1 \alpha$ knock-out mice, for the cortical neuronal cytoarchitecture to be absent or dramatically disturbed while thalamocortical afferent patterning is mostly intact (CX-NR1 and PLC $\beta 1$ mutants are similar). The small anterior barrels are also typically more disturbed than the larger barrels in the posterior medial barrel subfield (Erzurumlu and Kind, 2001; Hannan et al., 2001). The barrel deficits observed in RIM1 $\alpha$ knock-outs 
are therefore not as severe as in some mutants but are also not atypical. Even perturbations that are thought to specifically affect thalamic afferent terminals and not cortical neurons cause more dramatic effects on the small barrels and postsynaptic barrel cytoarchitecture than presynaptic thalamocortical afferent clustering of the large posterior medial barrels (Salichon et al., 2001). Nonetheless, the greater effect of mutating RIM1 $\alpha$ on postsynaptic cortical barrel cytoarchitecture than on presynaptic TCA clustering could be attributable to a purely cortical role of RIM1 $\alpha$ on barrel development in which presynaptic function between cortical neurons is disturbed in RIM1 $\alpha$ mutants. The more profound defects in barrel map development and neurotransmitter release observed in barrelless compared with RIM1 $\alpha$ mutants suggests that AC1 signaling is mediated through presynaptic pathways beyond RIM $1 \alpha$, perhaps other RIMs, or combines with established postsynaptic pathways mediated by $\mathrm{ACl}$ ( $\mathrm{Lu}$ et al., 2003) to produce a more dramatic barrel phenotype.

\section{Cortical role in barrel map formation}

Some have argued that factors intrinsic to the cortex instruct sensory map formation (Fukuchi-Shimogori and Grove, 2001), whereas others contend that barrel map features depend on, at least in part, signals communicated by thalamic axons (LopezBendito and Molnar, 2003). The segregation of TCAs in Cx-NR1 KO mice is fuzzy, with TCA arbors that are more diffuse than normal (Iwasato et al., 2000; Lee et al., 2005). This observation suggests that cortical NR1 is required for the maintenance and refinement of TCA arbors, and that communication between TCAs and layer IV neurons is crucial for the development of a barrel pattern. This situation is likely to be the case for barrelless as well. Previously, we showed that NMDAR-dependent LTP at thalamocortical synapses requires postsynaptic PKA activity and is difficult to induce in barrelless mice, probably because of an inability to properly regulate AMPAR trafficking (Lu et al., 2003). This LTP defect, as is captured in our model (Fig. 7F), can mask activity-dependent signals responsible for the regulated addition or elimination of particular synaptic targets on the postsynaptic neuron. In a mutation that only affects postsynaptic neurons, one might expect that the asymmetric orienting of dendrites from layer IV cortical neurons into barrel hollows is more severely affected than the clustering of presynaptic afferents into a barrel pattern. For instance, Cx-NR1 mutant mice completely lack postsynaptic layer IV barrel cytoarchitecture, but TCAs still aggregate to form a rudimentary barrel pattern (Iwasato et al., 2000). The complete absence of both presynaptic and postsynaptic barrel patterning in barrelless (AC1) mutants suggests that presynaptic $\mathrm{AC} 1$ function plays an important role in the barrelless phenotype. This issue will not be fully resolved, however, until thalamus-specific or cortex-specific AC1 mutants are developed and tested.

\section{How do afferents instruct their postsynaptic partners to form barrels?}

TCAs that innervate the barrel field initially (approximately P2P3) have relatively diffuse projections, and the progressive addition of branches and synapses at the cortical location corresponding to the mapped facial whisker and the commensurate elimination of inappropriate branches (Senft and Woolsey, 1991; Agmon et al., 1995; Rebsam et al., 2002) in an NMDA receptordependent manner (Lee et al., 2005) generate an afferent barrel pattern. The extensive tangential coverage of arbors from single barrelless thalamocortical afferents (Welker et al., 1996) is similar to the enlarged retinal ganglion cell (RGC) axon projection in the superior colliculus of barrelless mutants (Ravary et al., 2003; Plas et al., 2004), and RGC arbors after retinal activity blockade in a variety of species (O'Leary et al., 1986; Sretavan et al., 1988). The pattern of RGC activity is crucial, not just its presence, because enlarged projections are found when correlated retinal waves are eliminated but uncorrelated spontaneous RGC activity persists (McLaughlin et al., 2003; Chandrasekaran et al., 2005). In the frog optic tectum, visual activity governs the development of axonal projections by altering the retraction dynamics of axon terminals (Ruthazer et al., 2003). The establishment and maintenance of sensory maps are also perturbed when the excitability of sensory neurons is diminished (Yu et al., 2004; Hua et al., 2005), and neurons that cannot release neurotransmitter fail to recruit postsynaptic AMPARs (Harms et al., 2005) or maintain their central connections. The barrelless phenotype is likely attributable to similar barriers in this activity-dependent process.

How do deficits in presynaptic function interfere with barrel map development? Our model demonstrates that interfering with neurotransmitter release disrupts the balance between spike timing-dependent LTP and LTD and prevents thalamocortical afferents with correlated postsynaptic activity from strengthening, which is necessary for segregation to occur (Fig. 7). Thus, sufficient disruption of presynaptic function will interfere with Hebbian circuit development, as will direct intervention with postsynaptic plasticity mechanisms. Interestingly, neurons that cannot release neurotransmitter, in a competitive scenario, are able to form synapses but fail to recruit postsynaptic AMPARs (Harms et al., 2005). It is a common feature of many sensory pathways for thalamocortical afferents to have relatively high release probability and potent short-term depression (Stratford et al., 1996; Gil et al., 1999; Amitai, 2001; Iwasaki and Takahashi, 2001; Chung et al., 2002; Murphy et al., 2004). We propose that high release probability at TC synapses permits postsynaptic partners to use a correlation-based mechanism to mediate circuit development. Presumably, the activity-dependent development of other sensory maps, including ocular dominance columns and retinotopic maps, relies on afferents having high release probability and are similarly sensitive to perturbations that interfere with presynaptic function.

\section{References}

Abbott LF, Nelson SB (2000) Synaptic plasticity: taming the beast. Nat Neurosci [Suppl] 3:1178-1183.

Abdel-Majid RM, Leong WL, Schalkwyk LC, Smallman DS, Wong ST, Storm DR, Fine A, Dobson MJ, Guernsey DL, Neumann PE (1998) Loss of adenylyl cyclase I activity disrupts patterning of mouse somatosensory cortex. Nat Genet 19:289-291.

Agmon A, Yang LT, Jones EG, O'Dowd DK (1995) Topological precision in the thalamic projection to neonatal mouse barrel cortex. J Neurosci 15:549-561.

Amitai Y (2001) Thalamocortical synaptic connections: efficacy, modulation, inhibition and plasticity. Rev Neurosci 12:159-173.

Boczan J, Leenders AG, Sheng ZH (2004) Phosphorylation of syntaphilin by cAMP-dependent protein kinase modulates its interaction with syntaxin-1 and annuls its inhibitory effect on vesicle exocytosis. J Biol Chem 279:18911-18919.

Calakos N, Schoch S, Sudhof TC, Malenka RC (2004) Multiple roles for the active zone protein RIMlalpha in late stages of neurotransmitter release. Neuron 42:889-896.

Castillo PE, Schoch S, Schmitz F, Sudhof TC, Malenka RC (2002) RIMlalpha is required for presynaptic long-term potentiation. Nature 415:327-330.

Chandrasekaran AR, Plas DT, Gonzalez E, Crair MC (2005) Evidence for an instructive role of retinal activity in retinotopic map refinement in the superior colliculus of the mouse. J Neurosci 25:6929-6938.

Chen C, Blitz DM, Regehr WG (2002) Contributions of receptor desensiti- 
zation and saturation to plasticity at the retinogeniculate synapse. Neuron 33:779-788.

Chheda MG, Ashery U, Thakur P, Rettig J, Sheng ZH (2001) Phosphorylation of Snapin by PKA modulates its interaction with the SNARE complex. Nat Cell Biol 3:331-338.

Chi P, Greengard P, Ryan TA (2001) Synapsin dispersion and reclustering during synaptic activity. Nat Neurosci 4:1187-1193.

Chung S, Li X, Nelson SB (2002) Short-term depression at thalamocortical synapses contributes to rapid adaptation of cortical sensory responses in vivo. Neuron 34:437-446.

Crair MC, Malenka RC (1995) A critical period for long-term potentiation at thalamocortical synapses. Nature 375:325-328.

Czernik AJ, Pang DT, Greengard P (1987) Amino acid sequences surrounding the cAMP-dependent and calcium/calmodulin-dependent phosphorylation sites in rat and bovine synapsin I. Proc Natl Acad Sci USA 84:7518-7522.

Dan Y, Poo MM (2004) Spike timing-dependent plasticity of neural circuits. Neuron 44:23-30.

Datwani A, Iwasato T, Itohara S, Erzurumlu RS (2002) NMDA receptordependent pattern transfer from afferents to postsynaptic cells and dendritic differentiation in the barrel cortex. Mol Cell Neurosci 21:477-492.

Dodge Jr FA, Rahamimoff R (1967) Co-operative action a calcium ions in transmitter release at the neuromuscular junction. J Physiol (Lond) 193:419-432.

Erzurumlu RS, Kind PC (2001) Neural activity: sculptor of "barrels" in the neocortex. Trends Neurosci 24:589-595.

Evans GJ, Wilkinson MC, Graham ME, Turner KM, Chamberlain LH, Burgoyne RD, Morgan A (2001) Phosphorylation of cysteine string protein by protein kinase A. Implications for the modulation of exocytosis. J Biol Chem 276:47877-47885.

Feldman DE (2000) Timing-based LTP and LTD at vertical inputs to layer II/III pyramidal cells in rat barrel cortex. Neuron 27:45-56.

Feng J, Chi P, Blanpied TA, Xu Y, Magarinos AM, Ferreira A, Takahashi RH, Kao HT, McEwen BS, Ryan TA, Augustine GJ, Greengard P (2002) Regulation of neurotransmitter release by synapsin III. J Neurosci 22:4372-4380.

Foeller E, Feldman DE (2004) Synaptic basis for developmental plasticity in somatosensory cortex. Curr Opin Neurobiol 14:89-95.

Fukuchi-Shimogori T, Grove EA (2001) Neocortex patterning by the secreted signaling molecule FGF8. Science 294:1071-1074.

Gil Z, Connors BW, Amitai Y (1999) Efficacy of thalamocortical and intracortical synaptic connections: quanta, innervation, and reliability. Neuron 23:385-397.

Greengard P (1987) Neuronal phosphoproteins. Mediators of signal transduction. Mol Neurobiol 1:81-119.

Hannan AJ, Blakemore C, Katsnelson A, Vitalis T, Huber KM, Bear M, Roder J, Kim D, Shin HS, Kind PC (2001) PLC-beta1, activated via mGluRs, mediates activity-dependent differentiation in cerebral cortex. Nat Neurosci 4:282-288.

Harms KJ, Tovar KR, Craig AM (2005) Synapse-specific regulation of AMPA receptor subunit composition by activity. J Neurosci 25:6379-6388.

Hepp R, Cabaniols JP, Roche PA (2002) Differential phosphorylation of SNAP-25 in vivo by protein kinase C and protein kinase A. FEBS Lett 532:52-56.

Hessler NA, Shirke AM, Malinow R (1993) The probability of transmitter release at a mammalian central synapse. Nature 366:569-572.

Hilfiker S, Pieribone VA, Czernik AJ, Kao HT, Augustine GJ, Greengard P (1999) Synapsins as regulators of neurotransmitter release. Philos Trans R Soc Lond B Biol Sci 354:269-279.

Hosaka M, Hammer RE, Sudhof TC (1999) A phospho-switch controls the dynamic association of synapsins with synaptic vesicles. Neuron 24:377-387.

Hua JY, Smear MC, Baier H, Smith SJ (2005) Regulation of axon growth in vivo by activity-based competition. Nature 434:1022-1026.

Iwasaki S, Takahashi T (2001) Developmental regulation of transmitter release at the calyx of Held in rat auditory brainstem. J Physiol (Lond) 534:861-871.

Iwasato T, Datwani A, Wolf AM, Nishiyama H, Taguchi Y, Tonegawa S, Knopfel T, Erzurumlu RS, Itohara S (2000) Cortex-restricted disruption of NMDAR1 impairs neuronal patterns in the barrel cortex. Nature 406:726-731.
Jovanovic JN, Sihra TS, Nairn AC, Hemmings Jr HC, Greengard P, Czernik AJ (2001) Opposing changes in phosphorylation of specific sites in synapsin I during $\mathrm{Ca}^{2+}$-dependent glutamate release in isolated nerve terminals. J Neurosci 21:7944-7953.

Katz LC, Shatz CJ (1996) Synaptic activity and the construction of cortical circuits. Science 274:1133-1138.

Kidd FL, Isaac JT (1999) Developmental and activity-dependent regulation of kainate receptors at thalamocortical synapses. Nature 400:569-573.

Killackey HP, Leshin S (1975) The organization of specific thalamocortical projections to the posteromedial barrel subfield of the rat somatic sensory cortex. Brain Res 86:469-472.

Lao G, Scheuss V, Gerwin CM, Su Q, Mochida S, Rettig J, Sheng ZH (2000) Syntaphilin: a syntaxin-1 clamp that controls SNARE assembly. Neuron 25:191-201.

Lee LJ, Iwasato T, Itohara S, Erzurumlu RS (2005) Exuberant thalamocortical axon arborization in cortex-specific NMDAR1 knockout mice. J Comp Neurol 485:280-292.

Li L, Chin LS, Shupliakov O, Brodin L, Sihra TS, Hvalby O, Jensen V, Zheng D, McNamara JO, Greengard P, Andersen P (1995) Impairment of synaptic vesicle clustering and of synaptic transmission, and increased seizure propensity, in synapsin I-deficient mice. Proc Natl Acad Sci USA 92:9235-9239.

Lonart G (2002) RIM1: an edge for presynaptic plasticity. Trends Neurosci 25:329-332.

Lonart G, Sudhof TC (1998) Region-specific phosphorylation of rabphilin in mossy fiber nerve terminals of the hippocampus. J Neurosci 18:634-640.

Lonart G, Sudhof TC (2001) Characterization of rabphilin phosphorylation using phospho-specific antibodies. Neuropharmacology 41:643-649.

Lonart G, Schoch S, Kaeser PS, Larkin CJ, Sudhof TC, Linden DJ (2003) Phosphorylation of RIMlalpha by PKA triggers presynaptic long-term potentiation at cerebellar parallel fiber synapses. Cell 115:49-60.

Lopez-Bendito G, Molnar Z (2003) Thalamocortical development: how are we going to get there? Nat Rev Neurosci 4:276-289.

Lu HC, Gonzalez E, Crair MC (2001) Barrel cortex critical period plasticity is independent of changes in NMDA receptor subunit composition. Neuron 32:619-634.

Lu HC, She WC, Plas DT, Neumann PE, Janz R, Crair MC (2003) Adenylyl cyclase I regulates AMPA receptor trafficking during mouse cortical 'barrel' map development. Nat Neurosci 6:939-947.

Manabe T, Nicoll RA (1994) Long-term potentiation: evidence against an increase in transmitter release probability in the CA1 region of the hippocampus. Science 265:1888-1892.

McLaughlin T, Torborg CL, Feller MB, O'Leary DD (2003) Retinotopic map refinement requires spontaneous retinal waves during a brief critical period of development. Neuron 40:1147-1160.

Murphy GJ, Glickfeld LL, Balsen Z, Isaacson JS (2004) Sensory neuron signaling to the brain: properties of transmitter release from olfactory nerve terminals. J Neurosci 24:3023-3030.

Nagy G, Reim K, Matti U, Brose N, Binz T, Rettig J, Neher E, Sorensen JB (2004) Regulation of releasable vesicle pool sizes by protein kinase A-dependent phosphorylation of SNAP-25. Neuron 41:417-429.

O'Leary DD, Fawcett JW, Cowan WM (1986) Topographic targeting errors in the retinocollicular projection and their elimination by selective ganglion cell death. J Neurosci 6:3692-3705.

Ozaki N, Shibasaki T, Kashima Y, Miki T, Takahashi K, Ueno H, Sunaga Y, Yano H, Matsuura Y, Iwanaga T, Takai Y, Seino S (2000) cAMP-GEFII is a direct target of cAMP in regulated exocytosis. Nat Cell Biol 2:805-811.

Persico AM, Mengual E, Moessner R, Hall FS, Revay RS, Sora I, Arellano J, DeFelipe J, Gimenez-Amaya JM, Conciatori M, Marino R, Baldi A, Cabib S, Pascucci T, Uhl GR, Murphy DL, Lesch KP, Keller F, Hall SF (2001) Barrel pattern formation requires serotonin uptake by thalamocortical afferents, and not vesicular monoamine release. J Neurosci 21:6862-6873.

Pinto DJ, Hartings JA, Brumberg JC, Simons DJ (2003) Cortical damping: analysis of thalamocortical response transformations in rodent barrel cortex. Cereb Cortex 13:33-44.

Plas DT, Visel A, Gonzalez E, She WC, Crair MC (2004) Adenylate cyclase 1 dependent refinement of retinotopic maps in the mouse. Vision Res 44:3357-3364.

Ravary A, Muzerelle A, Herve D, Pascoli V, Ba-Charvet KN, Girault JA, 
Welker E, Gaspar P (2003) Adenylate cyclase 1 as a key actor in the refinement of retinal projection maps. J Neurosci 23:2228-2238.

Rebsam A, Seif I, Gaspar P (2002) Refinement of thalamocortical arbors and emergence of barrel domains in the primary somatosensory cortex: a study of normal and monoamine oxidase a knock-out mice. J Neurosci 22:8541-8552.

Reid CA, Bekkers JM, Clements JD (1998) N- and P/Q-type $\mathrm{Ca}^{2+}$ channels mediate transmitter release with a similar cooperativity at rat hippocampal autapses. J Neurosci 18:2849-2855.

Rhoades RW, Bennett-Clarke CA, Shi MY, Mooney RD (1994) Effects of 5-HT on thalamocortical synaptic transmission in the developing rat. J Neurophysiol 72:2438-2450.

Risinger C, Bennett MK (1999) Differential phosphorylation of syntaxin and synaptosome-associated protein of $25 \mathrm{kDa}$ (SNAP-25) isoforms. J Neurochem 72:614-624.

Rosahl TW, Geppert M, Spillane D, Herz J, Hammer RE, Malenka RC, Sudhof TC (1993) Short-term synaptic plasticity is altered in mice lacking synapsin I. Cell 75:661-670.

Rosahl TW, Spillane D, Missler M, Herz J, Selig DK, Wolff JR, Hammer RE, Malenka RC, Sudhof TC (1995) Essential functions of synapsins I and II in synaptic vesicle regulation. Nature 375:488-493.

Rosenmund C, Clements JD, Westbrook GL (1993) Nonuniform probability of glutamate release at a hippocampal synapse. Science 262:754-757.

Rozov A, Burnashev N, Sakmann B, Neher E (2001) Transmitter release modulation by intracellular $\mathrm{Ca}^{2+}$ buffers in facilitating and depressing nerve terminals of pyramidal cells in layer $2 / 3$ of the rat neocortex indicates a target cell-specific difference in presynaptic calcium dynamics. J Physiol (Lond) 531:807-826.

Ruthazer ES, Akerman CJ, Cline HT (2003) Control of axon branch dynamics by correlated activity in vivo. Science 301:66-70.

Salichon N, Gaspar P, Upton AL, Picaud S, Hanoun N, Hamon M, De Maeyer E, Murphy DL, Mossner R, Lesch KP, Hen R, Seif I (2001) Excess activation of serotonin $(5-\mathrm{HT}) 1 \mathrm{~B}$ receptors disrupts the formation of sensory maps in monoamine oxidase A and 5-HT transporter knock-out mice. J Neurosci 21:884-896.

Schlaggar BL, O’Leary DD (1991) Potential of visual cortex to develop an array of functional units unique to somatosensory cortex. Science 252:1556-1560.

Schluter OM, Schnell E, Verhage M, Tzonopoulos T, Nicoll RA, Janz R, Malenka RC, Geppert M, Sudhof TC (1999) Rabphilin knock-out mice reveal that rabphilin is not required for rab3 function in regulating neurotransmitter release. J Neurosci 19:5834-5846.

Schoch S, Castillo PE, Jo T, Mukherjee K, Geppert M, Wang Y, Schmitz F, Malenka RC, Sudhof TC (2002) RIMlalpha forms a protein scaffold for regulating neurotransmitter release at the active zone. Nature 415:321-326.
Senft SL, Woolsey TA (1991) Growth of thalamic afferents into mouse barrel cortex. Cereb Cortex 1:308-335.

Simons DJ, Carvell GE (1989) Thalamocortical response transformation in the rat vibrissa/barrel system. J Neurophysiol 61:311-330.

Sretavan DW, Shatz CJ, Stryker MP (1988) Modification of retinal ganglion cell axon morphology by prenatal infusion of tetrodotoxin. Nature 336:468-471.

Stratford KJ, Tarczy-Hornoch K, Martin KA, Bannister NJ, Jack JJ (1996) Excitatory synaptic inputs to spiny stellate cells in cat visual cortex. Nature 382:258-261.

Van der Loos H, Dorfl J (1978) Does the skin tell the somatosensory cortex how to construct a map of the periphery? Neurosci Lett 7:23-30.

Van der Loos H, Dorfl J, Welker E (1984) Variation in pattern of mystacial vibrissae in mice. A quantitative study of ICR stock and several inbred strains. J Hered 75:326-336.

Van der Loos H, Welker E, Dorfl J, Rumo G (1986) Selective breeding for variations in patterns of mystacial vibrissae of mice. Bilaterally symmetrical strains derived from ICR stock. J Hered 77:66-82.

Wang Y, Sudhof TC (2003) Genomic definition of RIM proteins: evolutionary amplification of a family of synaptic regulatory proteins. Genomics 81:126-137.

Welker E, Armstrong-James M, Bronchti G, Qurednik W, GheorghitaBaechler F, Dubois R, Guernsey DL, Van der Loos H, Neumann PE (1996) Altered sensory processing in the somatosensory cortex of the mouse mutant barrelless. Science 271:1864-1867.

Wolfel M, Schneggenburger R (2003) Presynaptic capacitance measurements and $\mathrm{Ca}^{2+}$ uncaging reveal submillisecond exocytosis kinetics and characterize the $\mathrm{Ca}^{2+}$ sensitivity of vesicle pool depletion at a fast CNS synapse. J Neurosci 23:7059-7068.

Woolsey TA, Van der Loos H (1970) The structural organization of layer IV in the somatosensory region (SI) of the mouse cerebral cortex. Brain Res 17:205-242.

Yanagisawa T, Tsumoto T, Kimura F (2004) Transiently higher release probability during critical period at thalamocortical synapses in the mouse barrel cortex: relevance to differential short-term plasticity of AMPA and NMDA EPSCs and possible involvement of silent synapses. Eur J Neurosci 20:3006-3018.

Yu CR, Power J, Barnea G, O’Donnell S, Brown HE, Osborne J, Axel R, Gogos JA (2004) Spontaneous neural activity is required for the establishment and maintenance of the olfactory sensory map. Neuron 42:553-566.

Zhang LI, Tao HW, Holt CE, Harris WA, Poo M (1998) A critical window for cooperation and competition among developing retinotectal synapses. Nature 395:37-44.

Zucker RS, Regehr WG (2002) Short-term synaptic plasticity. Annu Rev Physiol 64:355-405. 